\title{
Normal Modes of Poly(L-valine) in Relation to Spectra of Oligovalines
}

\author{
Leena Burman, Poonam Tandon, V. D. Gupta, ${ }^{\dagger}$ \\ Shantanu Rastogi, and Seema Srivastava
}

Physics Department, Lucknow University, Lucknow 226007 , India

(Received September 5, 1994)

\begin{abstract}
Poly(L-valine) (PLV) belongs to the class of polyamino acids having a bulky side chain. It preferably adopts $\beta$-sheet conformation, although high molecular weight PLV may form an $\alpha$ helix as well. In the present communication we report a detailed study of the phonons and their dispersion for $\beta$-PLV and the spectra of oligovalines in relation to its polymeric form. The $N$-deuterated analog of $\beta$-PLV has also been studied to confirm the correctness of assignments and force-field. Density-of-states and heat capacity have been obtained. The heat capacity is in very good agreement with the experimental measurements of Roles et al.
\end{abstract}

KEY WORDS Conformation / Phonon Dispersion / Specific Heat / Normal Mode Analysis / Poly(L-valine) / Density of States / Oligovalines /

Poly(L-valine) (PLV) is an example of a polyamino-acid having hydrophobic side chain (Figure 1) and it is preferably found to exist in an antiparallel $\beta$ sheet conformation. Conformational calculations on various degree of polymerization $^{1,2}$ and X-ray structure data ${ }^{3}$ have demonstrated that high molecular weight poly(L-valine) may form an $\alpha$ helix as well. $\beta$-PLV has an orthogonal lattice of unit cell dimensions $a=4.80 \AA, b=19.14 \AA$, and $c=$ $6.59 \AA$ with space group $\mathrm{P}_{2_{12} 2_{2}{ }_{1}}$ and $\mathrm{D}_{2}$ point group. ${ }^{4}$ It has a two fold screw axis and the chains are packed in an antiparallel arrangement. The neighbouring chains are hydrogen bonded via $\mathrm{N}-\mathrm{H} \cdots \mathrm{O}=\mathrm{C}$. There is a strong coupling of main chain vibrations with the side chain vibrations in the low frequency region and a detailed vibrational analysis is essential for definite assignment of the bands.

In some recent publications Wunderlich and $\mathrm{Bu},{ }^{5} \mathrm{Bu}$ et al., ${ }^{6}$ Roles and Wunderlich, ${ }^{7}$ and Roles et al. ${ }^{8}$ have reported experimental and theoretical studies of heat capacities of a variety of polymeric systems, synthetic as well as biopolymeric. In most of the cases, their analysis is based on separation of the vibrational spectrum into group and skeletal vibrations. The former are taken from computations fitted to IR and Raman data and the latter by

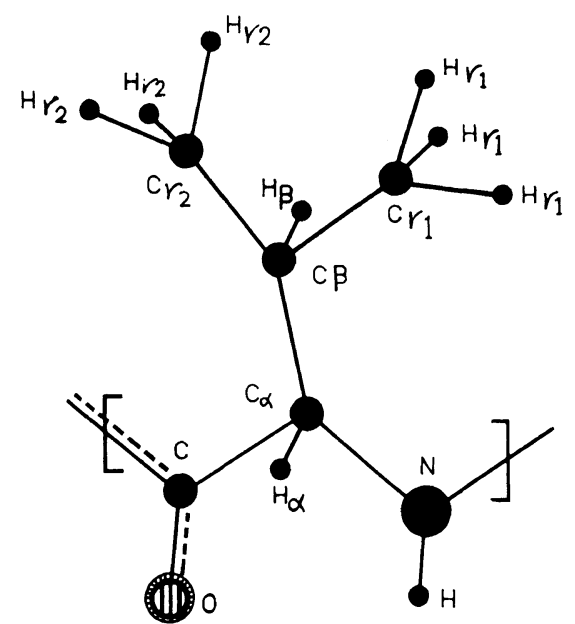

Figure 1. Chemical repeat unit of Poly(L-valine).

\footnotetext{
† To whom all correspondence should be addressed.
} 
using the two parameter Tarasov model and fitting to low temperature heat capacities. However, in a few cases, where detailed dispersion curves of the vibrational spectrum are available, ${ }^{9-13}$ they have been used for obtaining group and skeletal vibrations and number of vibrators of each type. In some cases, dispersion curves for one polymeric system have been used to obtain the number of vibrators and frequencies of box oscillators for polymers with identical backbone. This approach is allowed when full dispersion curves are not available. However, it has its own limitations, specially when the side-chain and backbone modes are strongly coupled. In the present communication we report a comprehensive study of the normal mode analysis of $\beta$-PLV using Urey Bradley force field, its $N$ deuterated analog, phonon dispersion curves, spectra of oligovalines in relation to the polymeric form and specific heat from the density-of-states derived from the dispersion curves.

\section{THEORY AND EXPERIMENT}

\section{Calculation of Normal Mode Frequencies}

The calculation of normal mode frequencies has been carried out according to Wilson's G.
F. matrix method ${ }^{14}$ as modified by Higgs ${ }^{15}$ for an infinite chain. The vibrational secular equation which gives normal mode frequencies and their dispersion as a function of phase angles has the form:

$$
[G(\delta) F(\delta)-\lambda(\delta) I]=0, \quad 0 \leq \delta \leq \pi
$$

where $G$ is the inverse of the kinetic energy matrix, $F$ is the force field matrix, $\delta$ is the vibrational phase difference between the corresponding modes of the adjacent residue units.

The vibrational frequencies $v(\delta)$ (in $\mathrm{cm}^{-1}$ ) are related to eigen values $\lambda(\delta)$ by the following relation:

$$
\lambda(\delta)=4 \pi^{2} c^{2} v^{2}(\delta)
$$

The calculated frequencies at $\delta=0$ are matched with the observed infrared frequencies. The FT-IR spectrum (Figure 2) of $\beta$-PLV, obtained from Sigma Chemicals, U.S.A. (Lot $111 \mathrm{H} 5536, D P$ (vis) 82 and $M W$ (vis) 8100 ) has been recorded in the $4000-450 \mathrm{~cm}^{-1}$ frequency range in CsI on a Perkin Elmer 1800 spectrophotometer, which was purged with dry nitrogen gas before recording the spectrum.

The FT-IR spectra of poly(L-valine) and oligovalines have been obtained in the solid state. It is well studied and established that

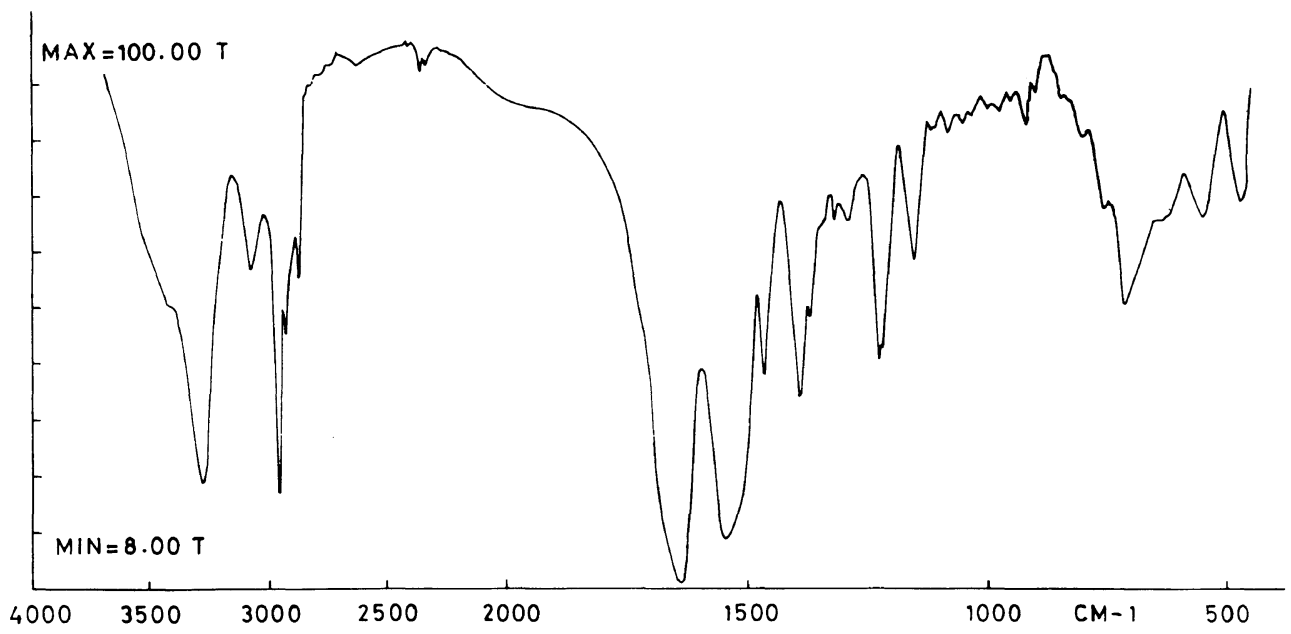

Figure 2. F.T.I.R. spectra of Poly(L-valine) $\left(4000-450 \mathrm{~cm}^{-1}\right)$. 
Normal Modes of Poly(L-valine) and Oligovalines

Table I. Internal coordinates and force constants $\left(\mathrm{md} \AA^{-1}\right)^{\mathrm{a}}$

\begin{tabular}{llll}
\hline$(\mathrm{C}=\mathrm{N})$ & 5.600 & $\phi(\mathrm{O}=\mathrm{C}-\mathrm{C} \alpha)$ & $0.200(0.60)$ \\
$\nu(\mathrm{C} \alpha-\mathrm{N})$ & 2.800 & $\phi(\mathrm{O}=\mathrm{C}=\mathrm{N})$ & $0.330(0.90)$ \\
$\nu(\mathrm{C} \alpha-\mathrm{C} \beta)$ & 2.600 & $\phi(\mathrm{C} \alpha-\mathrm{C}=\mathrm{N})$ & $0.210(0.60)$ \\
$\nu\left(\mathrm{C} \beta-\mathrm{C} \gamma_{1}\right)$ & 2.000 & $\phi\left(\mathrm{C} \gamma_{1}-\mathrm{C} \beta-\mathrm{C} \gamma_{2}\right)$ & $0.340(0.20)$ \\
$v\left(\mathrm{C} \beta-\mathrm{C} \gamma_{2}\right)$ & 2.000 & $\phi\left(\mathrm{C} \gamma_{1}-\mathrm{C} \beta-\mathrm{H} \beta\right)$ & $0.510(0.22)$ \\
$v(\mathrm{H}-\mathrm{H})$ & 5.360 & $\phi\left(\mathrm{C} \gamma_{2}-\mathrm{C} \beta-\mathrm{H} \beta\right)$ & $0.510(0.22)$ \\
$v(\mathrm{H} \alpha-\mathrm{C} \alpha)$ & 4.155 & $\phi(\mathrm{H} \beta-\mathrm{C} \beta-\mathrm{C} \alpha)$ & $0.440(0.22)$ \\
$v(\mathrm{H} \beta-\mathrm{C} \beta)$ & 4.410 & $\phi\left(\mathrm{C} \beta-\mathrm{C} \gamma_{1}-\mathrm{H} \gamma_{1}\right)$ & $0.420(0.22)$ \\
$v\left(\mathrm{H} \gamma_{1}-\mathrm{C} \gamma_{1}\right)$ & 4.210 & $\phi\left(\mathrm{C} \beta-\mathrm{C} \gamma_{2}-\mathrm{H} \gamma_{2}\right)$ & $0.420(0.22)$ \\
$v\left(\mathrm{H} \gamma_{2}-\mathrm{C} \gamma_{2}\right)$ & 4.210 & $\phi\left(\mathrm{H} \gamma_{1}-\mathrm{C} \gamma_{1}-\mathrm{H} \gamma_{1}\right)$ & $0.425(0.24)$ \\
$\nu(\mathrm{C} \alpha-\mathrm{C})$ & 2.200 & $\phi\left(\mathrm{H} \gamma_{2}-\mathrm{C} \gamma_{2}-\mathrm{H} \gamma_{2}\right)$ & $0.425(0.24)$ \\
$v(\mathrm{C}=\mathrm{O})$ & 8.225 & $\phi\left(\mathrm{C} \gamma_{1}-\mathrm{C} \beta-\mathrm{C} \alpha\right)$ & $0.210(0.20)$ \\
& & $\phi\left(\mathrm{C} \gamma_{2}-\mathrm{C} \beta-\mathrm{C} \alpha\right)$ & $0.210(0.20)$ \\
$\phi(\mathrm{H}-\mathrm{N}=\mathrm{C})$ & $\omega(\mathrm{N}-\mathrm{H})$ & 0.155 \\
$\phi(\mathrm{H}-\mathrm{N}-\mathrm{C} \alpha)$ & $0.380(0.60)$ & $\omega(\mathrm{C}=\mathrm{O})$ & 0.445 \\
$\phi(\mathrm{C}=\mathrm{N}-\mathrm{C} \alpha)$ & $0.345(0.50)$ & & \\
$\phi(\mathrm{N}-\mathrm{C} \alpha-\mathrm{H} \alpha)$ & $0.650(0.35)$ & $\tau(\mathrm{C} \alpha-\mathrm{C})$ & 0.067 \\
$\phi(\mathrm{C}-\mathrm{C} \alpha-\mathrm{H} \alpha)$ & $0.290(0.80)$ & $\tau(\mathrm{C}=\mathrm{N})$ & 0.027 \\
$\phi(\mathrm{N}-\mathrm{C} \alpha-\mathrm{C})$ & $0.270(0.48)$ & $\tau(\mathrm{C} \beta-\mathrm{C} \alpha)$ & 0.047 \\
$\phi(\mathrm{N}-\mathrm{C} \alpha-\mathrm{C} \beta)$ & $0.320(0.50)$ & $\tau\left(\mathrm{C} \beta-\mathrm{C} \gamma_{2}\right)$ & 0.008 \\
$\phi(\mathrm{C}-\mathrm{C} \alpha-\mathrm{C} \beta)$ & $0.100(0.50)$ & $\tau(\mathrm{N}-\mathrm{C} \alpha)$ & 0.008 \\
$\phi(\mathrm{C} \beta-\mathrm{C} \alpha-\mathrm{H} \alpha)$ & $0.440(0.20)$ & & 0.031 \\
& $0.270(0.22)$ & &
\end{tabular}

a $v, \phi, \omega, \tau$ denote stretch, angle bend, wag, and torsion, respectively. Non bonded force constants are given in parantheses.

for the degree of polymerization below 500 , poly(L-valine) goes into $\beta$ form. ${ }^{2,16}$ In the present case the degree of polymerization is 80 . The sample is highly crystalline as evinced by $\mathrm{X}$-ray diffraction and in $\beta$-form as seen from the characteristic Bragg reflections and amide bands, in particular amide III and V. Full use has been made of the dichroic information and our assignments are in complete agreement both at the zone centre (A species) and at the zone boundry (E species) with the observed data. Since the optically active modes correspond to phase values $\delta=0$ and $\delta=\pi$, a reasonably good matching is automatically obtained at $\delta=\pi$ by matching the observed frequencies at $\delta=0$. The frequencies below $450 \mathrm{~cm}^{-1}$ are matched with the FT-IR and Raman frequencies reported by Fanconi. ${ }^{17}$ The final force constants are shown in Table I. The dispersion curves below $1400 \mathrm{~cm}^{-1}$ are shown in Figures 3(a), 4(a), and 5(a).
Theory of Interpretation of Spectra of Oligomers One of the important uses of the dispersion curves is to interpret the spectra of short chain molecules or oligomers which have the same structure as the polymeric form. The infrared spectra of macromolecules containing a finite chain of identical structural units is characterized by a series of absorption bands. It can be shown that the normal modes responsible for a component absorption can be specified by an appropriate phase difference. ${ }^{18}$ They are denoted by $k$ values related to the phase difference $\delta$ along the chain between adjacent residue units and are given by

$$
\delta=(k \pi / n), \quad k=0,1,2, \cdots, n-1
$$

where $n$ is the number of repeat units in the chain and $k$ is an integer which represents the number of loops in a stationary wave representing the chain vibrations. The above equation holds good for finite chain having free ends. In the present paper, the disperision 
curves are used to calculate the normal frequencies of oligomers of valine upto hexamer for phase values given by eq 3 .

\section{Calculation of Heat Capacity}

Another use of dispersion curves is that microscopic behaviour of a crystal can be correlated with its macroscopic properties such as specific heat. For a one dimensional system the density of state function or the frequency distribution function, which expresses the way energy is distributed among the various branches of normal modes in the crystal, is calculated from the relation

$$
g(v)=\sum_{j}\left(\partial v_{j} / \partial \delta\right)^{-1} \mid v_{j}(\delta)=v
$$

The sum is over all branches $j$. Considering a solid as an assembly of harmonic oscillators, the frequency distribution $g(v)$ is equivalent to a partition function. It can be used to compute thermodynamic quantities such as free energy, entropy, specific heat, and enthalpy. The heat capacity, which can give information about the proportion of a protein which is in $\alpha$ helical or $\beta$ sheet structure and is necessary in evaluating the basic thermodynamics of enzyme reaction, ${ }^{19}$ has been calculated using Debye's relation

$$
C_{\mathrm{v}}=\sum_{j} g\left(v_{j}\right) k N_{\mathrm{A}}\left(h v_{j} / k T\right)^{2} \frac{\exp \left(h v_{j} / k T\right)}{\left[\exp \left(h v_{j} / k T\right)-1\right]^{2}}
$$

with

$$
\int g\left(v_{j}\right) \mathrm{d} v_{j}=1
$$

The constant volume heat capacity $C_{\mathrm{v}}$, given by eq 5 is converted into constant pressure heat capacity $C_{\mathrm{p}}$ using the Nernst-Lindemann approximation $^{20}$ :

$$
C_{\mathrm{p}}-C_{\mathrm{v}}=3 R A_{0}\left(C_{\mathrm{p}}^{2} T / C_{\mathrm{v}} T_{\mathrm{m}}^{0}\right)
$$

where $A_{0}$ is a constant of a universal value $3.9 \times 10^{-3}\left(\mathrm{kmol} \mathrm{J}^{-1}\right)$ and $T_{\mathrm{m}}^{0}$ is the estimated eqilibrium melting temperature, which is taken to be $573 \mathrm{~K}$.

\section{RESULTS AND DISCUSSION}

The unit cell of PLV chain consists of two repeat units. Since there are 16 atoms per residue, there would be $(3 \times 32-4)=92$ normal modes of vibrations. The vibrational frequencies were calculated for values of $\delta$ varying from 0 to $\pi$ in steps of $0.05 \pi$. The optically active modes are those for which $\delta=0$ or $\pi$. The four zero frequencies [Figure 5(a)] correspond the acoustic modes, three representing three translations and one rotation of the chain. Assignments of modes are based not only on the concept of group vibrations and potential energy distribution but also take into account line intensity, line profile, and second derivative spectra. For the sake of simplicity, it is convenient to discuss the normal vibrational frequenices under two heads viz. side chain modes and backbone modes.

\section{Backbone Modes}

The modes involving the motions of amide group and $\mathrm{N}-\mathrm{C} \alpha$ and $\mathrm{C}-\mathrm{C} \alpha$ stretches, $\mathrm{C}-\mathrm{C} \alpha-\mathrm{N}$ bending motions, and their mixtures are regarded as skeletal or backbone modes. The pure backbone modes, pure side chain modes and the mix modes along with their assignments are given in Table II, Table III, and Table IV, respectively. On comparison of the spectra of polyglycine $\mathrm{I},{ }^{10} \beta$-poly(L-alanine) ${ }^{14}$ and poly(L-valine), it is inferred that there is very little interaction between the main chain vibrations and side chain vibrations in the $1700-1200 \mathrm{~cm}^{-1}$ region (Table V). Below $1200 \mathrm{~cm}^{-1}$ there is a large influence of side chain vibrations on the vibrations of the main chain (Table IV).

The amide I absorption in the IR spectrum of $\beta$-poly( $\mathrm{L}$-valine) is reported at $1638 \mathrm{~cm}^{-1}$ by Yamashita and Yamashita ${ }^{1}$ and at $1625 \mathrm{~cm}^{-1}$ by Koenig and Sutton. ${ }^{21}$ The corresponding line in the Raman spectrum appears at $1666 \mathrm{~cm}^{-1}$. We have observed amide I line at $1638 \mathrm{~cm}^{-1}$ in the FT-IR spectra of $\beta$-PLV. Second derivative spectra showed splitting of 
Table II. Pure back-bone modes ${ }^{\mathrm{a}}$

\begin{tabular}{llll}
\hline Calcd & Obsd & \multicolumn{3}{c}{ Assignmen $\left(\%\right.$ P.E.D. $\left.{ }^{\mathrm{b}}\right)$} & $(\delta=0)$ \\
\hline 3289 & 3290 & $v(\mathrm{~N}-\mathrm{H})(99)$ & $\{$ Amide $\mathrm{A}\}$ \\
1629 & 1638 & $v(\mathrm{C}=\mathrm{N})(20)+v(\mathrm{C}=\mathrm{O})(64)$ & $\begin{array}{l}\text { Amide I } \\
\end{array}$ \\
1537 & 1545 & $v(\mathrm{C}=\mathrm{N})(20)+\phi(\mathrm{C}=\mathrm{N}-\mathrm{H})(37)+$ \\
& & $\phi(\mathrm{C} \alpha-\mathrm{N}-\mathrm{H})(36)$ & $\{$ Amide II \\
\hline
\end{tabular}

\begin{tabular}{lllc}
\hline Calcd & Obsd & \multicolumn{2}{c}{ Assignment (\% P.E.D.) $(\delta=\pi)$} \\
\hline 3289 & 3290 & $v(\mathrm{~N}-\mathrm{H})(100)$ & $\{$ Amide $\mathrm{A}\}$ \\
1631 & 1638 & $v(\mathrm{C}=\mathrm{N})(19)+v(\mathrm{C}=\mathrm{O})(63)+$ \\
& & $\phi(\mathrm{C}=\mathrm{N}-\mathrm{H})(5)$ & $\{$ Amide I \\
1531 & 1545 & $v(\mathrm{C}=\mathrm{N})(21)+\phi(\mathrm{C}=\mathrm{N}-\mathrm{H})(35)+$ \\
& & $\phi(\mathrm{C} \alpha-\mathrm{N}-\mathrm{H})(35)$ & $\{$ Amide II \\
\end{tabular}

a All frequencies are in $\mathrm{cm}^{-1}$.

b P.E.D., potential energy distribution.

Table III. Pure side-chain modes ${ }^{\mathrm{a}}$

\begin{tabular}{rrl}
\hline Calcd & Obsd & \multicolumn{1}{c}{ Assignment (\% P.E.D.) $(\delta=0)$} \\
\hline 2968 & 2967 & $v(\mathrm{C} \alpha-\mathrm{H} \alpha)(99)$ \\
2930 & 2935 & $v(\mathrm{C} \beta-\mathrm{H} \beta)(76)+v\left(\mathrm{C} \gamma_{1}-\mathrm{H} \gamma_{1}\right)(12)+v\left(\mathrm{C} \gamma_{2}-\mathrm{H} \gamma_{2}\right)(12)$ \\
2922 & & $v\left(\mathrm{C} \gamma_{1}-\mathrm{H} \gamma_{1}\right)(52)+v\left(\mathrm{C} \gamma_{2}-\mathrm{H} \gamma_{2}\right)(47)$ \\
2920 & & $v(\mathrm{C} \beta-\mathrm{H} \beta)(25)+v\left(\mathrm{C} \gamma_{1}-\mathrm{H} \gamma_{1}\right)(35)+v\left(\mathrm{C} \gamma_{2}-\mathrm{H} \gamma_{2}\right)(39)$ \\
2880 & 2876 & $v\left(\mathrm{C} \gamma_{1}-\mathrm{H} \gamma_{1}\right)(57)+v\left(\mathrm{C} \gamma_{2}-\mathrm{H} \gamma_{2}\right)(43)$ \\
2880 & & $v\left(\mathrm{C} \gamma_{1}-\mathrm{H} \gamma_{1}\right)(64)+v\left(\mathrm{C} \gamma_{2}-\mathrm{H} \gamma_{2}\right)(36)$ \\
2879 & & $v\left(\mathrm{C} \gamma_{1}-\mathrm{H} \gamma_{1}\right)(35)+v\left(\mathrm{C} \gamma_{2}-\mathrm{H} \gamma_{2}\right)(65)$ \\
2879 & & $v\left(\mathrm{C} \gamma_{1}-\mathrm{H} \gamma_{1}\right)(44)+v\left(\mathrm{C} \gamma_{2}-\mathrm{H} \gamma_{2}\right)(56)$ \\
1471 & 1470 & $\phi\left(\mathrm{H} \gamma_{1}-\mathrm{C} \gamma_{1}-\mathrm{H} \gamma_{1}\right)(45)+\phi\left(\mathrm{H} \gamma_{2}-\mathrm{C} \gamma_{2}-\mathrm{H} \gamma_{2}\right)(49)$ \\
1470 & & $\phi\left(\mathrm{H} \gamma_{1}-\mathrm{C} \gamma_{1}-\mathrm{H} \gamma_{1}\right)(28)+\phi\left(\mathrm{H} \gamma_{2}-\mathrm{C} \gamma_{2}-\mathrm{H} \gamma_{2}\right)(67)$ \\
1469 & & $\phi\left(\mathrm{H} \gamma_{1}-\mathrm{C} \gamma_{1}-\mathrm{H} \gamma_{1}\right)(67)+\phi\left(\mathrm{H} \gamma_{2}-\mathrm{C} \gamma_{2}-\mathrm{H} \gamma_{2}\right)(28)$ \\
1467 & & $\phi\left(\mathrm{H} \gamma_{1}-\mathrm{C} \gamma_{1}-\mathrm{H} \gamma_{1}\right)(50)+\phi\left(\mathrm{H} \gamma_{2}-\mathrm{C} \gamma_{2}-\mathrm{H} \gamma_{2}\right)(45)$ \\
1391 & 1394 & $\phi\left(\mathrm{C} \beta-\mathrm{C} \gamma_{1}-\mathrm{H} \gamma_{1}\right)(24)+\phi\left(\mathrm{C} \beta-\mathrm{C} \gamma_{2}-\mathrm{H} \gamma_{2}\right)(24)+\phi\left(\mathrm{H} \gamma_{2}-\mathrm{C} \gamma_{2}-\mathrm{H} \gamma_{2}\right)(23)+\phi\left(\mathrm{H} \gamma_{1}-\mathrm{C} \gamma_{1}-\mathrm{H} \gamma_{1}\right)(23)$ \\
1370 & 1372 & $\phi\left(\mathrm{C} \beta-\mathrm{C} \gamma_{1}-\mathrm{H} \gamma_{1}\right)(24)+\phi\left(\mathrm{C} \beta-\mathrm{C} \gamma_{2}-\mathrm{H} \gamma_{2}\right)(24)+\phi\left(\mathrm{H} \gamma_{1}-\mathrm{C} \gamma_{1}-\mathrm{H} \gamma_{1}\right)(23)+\phi\left(\mathrm{H} \gamma_{2}-\mathrm{C} \gamma_{2}-\mathrm{H} \gamma_{2}\right)(23)$ \\
1006 & 1006 & $\phi\left(\mathrm{C} \beta-\mathrm{C} \gamma_{1}-\mathrm{H} \gamma_{1}\right)(40)+\phi\left(\mathrm{C} \beta-\mathrm{C} \gamma_{2}-\mathrm{H} \gamma_{2}\right)(38)$ \\
970 & 981 & $v\left(\mathrm{C} \beta-\mathrm{C} \gamma_{1}\right)(13)+v\left(\mathrm{C} \beta-\mathrm{C} \gamma_{2}\right)(14)+\phi\left(\mathrm{C} \beta-\mathrm{C} \gamma_{2}-\mathrm{H} \gamma_{2}\right)(26)+\phi\left(\mathrm{C} \beta-\mathrm{C} \gamma_{1}-\mathrm{H} \gamma_{1}\right)(33)$ \\
918 & 907 & $\phi\left(\mathrm{C} \beta-\mathrm{C} \gamma_{1}-\mathrm{H} \gamma_{1}\right)(48)+\phi\left(\mathrm{C} \beta-\mathrm{C} \gamma_{2}-\mathrm{H} \gamma_{2}\right)(45)$ \\
845 & 852 & $v\left(\mathrm{C} \beta-\mathrm{C} \gamma_{1}\right)(27)+v\left(\mathrm{C} \beta-\mathrm{C} \gamma_{2}\right)(31)+\phi\left(\mathrm{C} \beta-\mathrm{C} \gamma_{2}-\mathrm{H} \gamma_{2}\right)(14)+\phi\left(\mathrm{C} \beta-\mathrm{C} \gamma_{1}-\mathrm{H} \gamma_{1}\right)(19)$ \\
199 & 200 & $\tau\left(\mathrm{C} \beta-\mathrm{C} \gamma_{1}\right)(31)+\tau\left(\mathrm{C} \beta-\mathrm{C} \gamma_{2}\right)(63)$ \\
\hline
\end{tabular}

a All frequencies are in $\mathrm{cm}^{-1}$.

amide I mode into four components viz. 1635, 1652,1670 , and $1687 \mathrm{~cm}^{-1}$. This splitting is due to intrachain and interchain hydrogen bonding between adjacent groups in the same chain and in the neighbouring chain. ${ }^{22}$ The amide II mode appears as a strong band at $1545 \mathrm{~cm}^{-1}$. Koenig and Sutton ${ }^{21}$ in their studies on poly(L-valine) initially suggested the splitting of amide III into four components viz. $1287,1276,1231$, and $1224 \mathrm{~cm}^{-1}$, later they revised the assignment of amide III after observing the shift in $N$-deuterated $\mathrm{PLV}^{23}$ and they assigned the mode at $1231 \mathrm{~cm}^{-1}$ to amide III. They observed that the line at 1231 and
$1276 \mathrm{~cm}^{-1}$ disappear at equal rate on deuteration. We disagree with this finding as the potential energy distribution of $1270 \mathrm{~cm}^{-1}$ mode indicates that it is purely a side chain mode. Our result agrees with the Fasman et al., ${ }^{2}$ as the $1270 \mathrm{~cm}^{-1}$ line, which is mainly $\mathrm{H} \beta$ bending mode according to normal mode analysis, is found in the spectra of a monomer and this cannot be due to peptide group as monomer has no peptide group. The line at $1270 \mathrm{~cm}^{-1}$ does not disappear on deuteration but shifts down to $1264 \mathrm{~cm}^{-1}$ in accordance with the Fasman $e t$ al. $^{2}$

We observe a strong band at $1228 \mathrm{~cm}^{-1}$, 


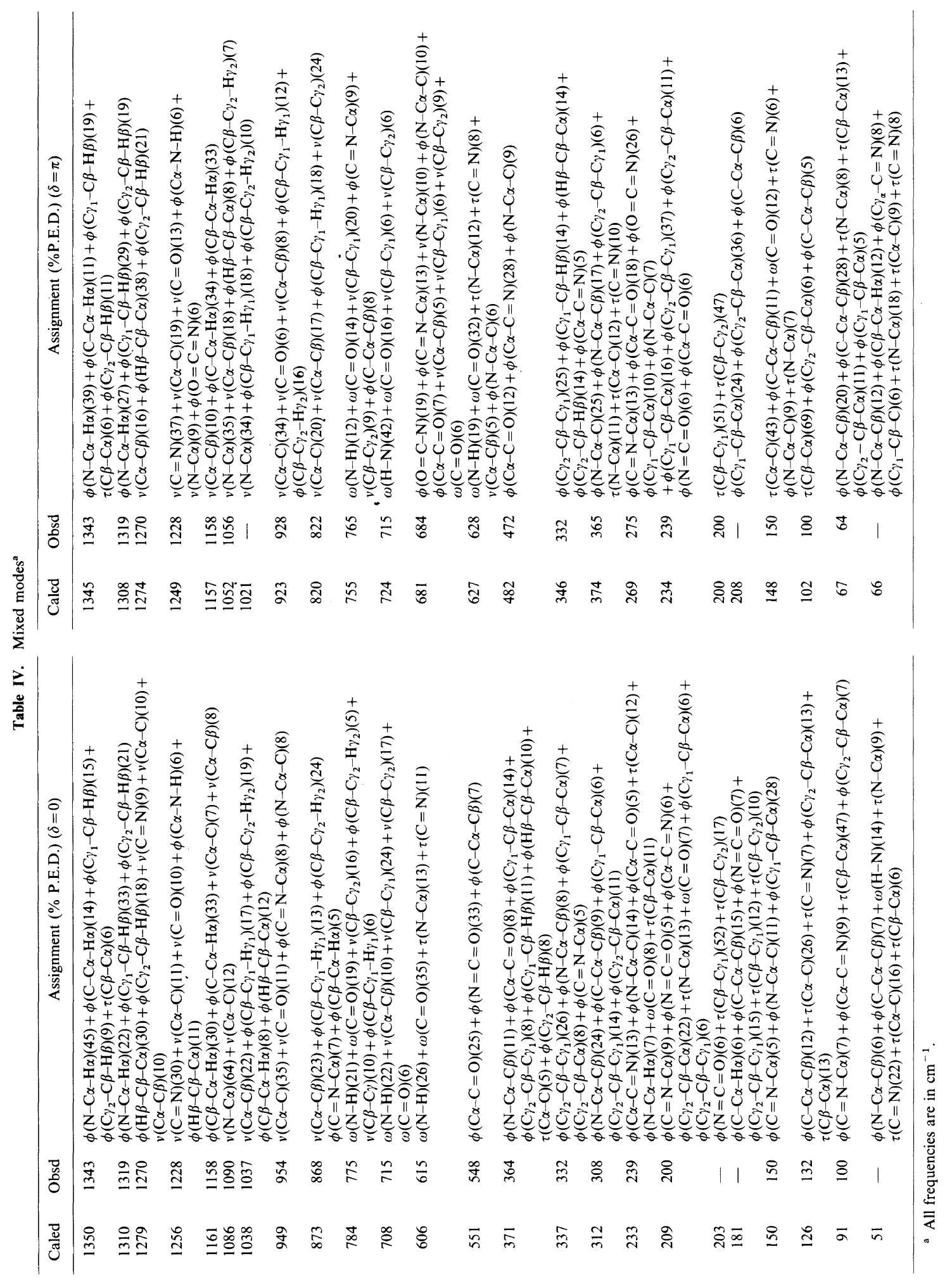


the characteristic frequency of amide III for the $\beta$ sheet conformation of poly(L-valine). The corresponding calculated frequency is at $1258 \mathrm{~cm}^{-1}$. In spite of our best efforts, this frequency could not be adjusted better. When PLV is deuterated the anide III mode shifts down to $1023 \mathrm{~cm}^{-1}$ (a shift of $235 \mathrm{~cm}^{-1}$ ) but the potential energy distribution of the shifted mode has small contribution of $\mathrm{N}-\mathrm{C} \alpha$ stretch also (Table VI). This is consistent with the fact that the line shape of the deuterated mode of amide III which shifts from $1231 \mathrm{~cm}^{-1}$ to 993 $\mathrm{cm}^{-1}$ (a shift of $238 \mathrm{~cm}^{-1}$ ) does not remain the same as is clear from the $N$-deuterated spectra of $\beta$-PLV reported by Koenig and Sutton. ${ }^{21}$ The $\mathrm{N}-\mathrm{H}$ stretching vibration which is observed at $3290 \mathrm{~cm}^{-1}$ in the nondeuterated samples shifts to $\mathrm{N}-\mathrm{D}$ mode at $2399 \mathrm{~cm}^{-1}$.

The amide $\mathrm{V}$ mode which is characteristic of

Table V. Amide modes of polypeptides in $\beta$ conformation $^{\mathbf{a}}$

\begin{tabular}{llll}
\hline & PGl & PLA & PLV \\
\hline Amide I & 1690 & 1695 & 1666 \\
& 1630 & 1634 & 1638 \\
Amide II & 1514 & 1524 & 1545 \\
& 1524 & & \\
Amide III & 1240 & 1224 & 1228 \\
& 1220 & 1241 & \\
\hline
\end{tabular}

a PGl, polyglycine I; PLA, poly(L-alanine); PLV, poly(L-valine). $\beta$ conformation in polyglycine, poly( $\mathrm{L}$-valine) is assigned at $715 \mathrm{~cm}^{-1}$. The frequency of amide $\mathrm{V}$ mode does not depend solely on main chain conformation but hydrogen bond strength and side chain structure in question also play an important role. ${ }^{22}$ Likewise the frequency of $\mathrm{CO}$ in-plane-bend (amide IV), $\mathrm{CO}$ out-of-plane bend (amide VI), and $\mathrm{CN}$ torsion (amide VII) also vary with structure. On $N$ deuteration the amide $\mathrm{V}$ mode in $\beta$-PLV disappears and $\omega(\mathrm{N}-\mathrm{D})$ mode appears at 530 $\mathrm{cm}^{-1}$. This agrees well with the finding of Itoh et al. ${ }^{24} \mathrm{~A}$ mixed mode of amide $\mathrm{V}+$ amide $\mathrm{VI}$ is assigned at $615 \mathrm{~cm}^{-1}$. The band observed at $472 \mathrm{~cm}^{-1}$ which is characteristic of $\beta$-PLV and is sensitive to the conformation of main chain, is calculated at $482 \mathrm{~cm}^{-1}(\delta=\pi)$. It is mainly $(\mathrm{C} \alpha-\mathrm{C}-\mathrm{N})$ bending mode. Itoh and Fasman ${ }^{16}$ have observed two modes at 262 and $235 \mathrm{~cm}^{-1}$ in IR spectra of $\beta$-PLV and have tentatively assigned these modes as main chain deformation. These modes are reproduced reasonably well as main chain deformation in our normal mode analysis.

An intense band at $132 \mathrm{~cm}^{-1}$ in the Raman spectrum is assigned to the torsional motion around the peptide $\mathrm{C}-\mathrm{N}$ bond (amide VII). This frequency belongs to $\delta=0$ as shown in Table IV. The corresponding frequency belonging to $\delta=\pi$ is calculated at $148 \mathrm{~cm}^{-1}$.

A normal mode involing $(\mathrm{N}-\mathrm{C} \alpha)(64 \%)$ and $(\mathrm{C} \alpha-\mathrm{C})(12 \%)$ stretches is calculated at 1086

Table VI. Shifts on $N$-deuteration ${ }^{\text {a }}$

\begin{tabular}{|c|c|}
\hline $\begin{array}{l}\text { Freq. }{ }^{\mathrm{b}} \text { of the } \\
\mathrm{N}-\mathrm{H} \text { mode }\end{array}$ & Assinment (\% P.E.D.) \\
\hline 3289 & $v(\mathrm{~N}-\mathrm{H})(99)$ \\
\hline 1537 & $\begin{array}{l}v(\mathrm{C}=\mathrm{N})(20)+\phi(\mathrm{C}=\mathrm{N}-\mathrm{H})(37)+ \\
\phi(\mathrm{C} \alpha-\mathrm{N}-\mathrm{H})(36)\end{array} \quad\{$ Amide II $\}$ \\
\hline 1256 & $\begin{array}{l}v(\mathrm{C}=\mathrm{N})(30)+v(\mathrm{C} \alpha-\mathrm{C})(11)+v(\mathrm{C}=\mathrm{O})(10)+ \\
\phi(\mathrm{C} \alpha-\mathrm{N}-\mathrm{H})(6)+\phi(\mathrm{H} \beta-\mathrm{C} \beta-\mathrm{C} \alpha)(11)\end{array}$ \\
\hline 708 & $\begin{array}{lr} & \{\text { Amide III }\} \\
\omega(\mathrm{N}-\mathrm{H})(22)+v(\mathrm{C} \beta-\mathrm{C} \gamma)(41)+\omega & (\mathrm{C}=\mathrm{O})(6)+ \\
v(\mathrm{C} \alpha-\mathrm{C} \beta)(10) & \{\text { Amide } \mathrm{V}\}\end{array}$ \\
\hline
\end{tabular}

\begin{tabular}{lll}
\hline $\begin{array}{l}\text { Freq. }{ }^{\mathrm{b}} \text { of the } \\
\text { N-D mode }\end{array}$ & \multicolumn{2}{c}{ Assignment $(\%$ P.E.D. $)$} \\
\hline 2399 & $v(\mathrm{~N}-\mathrm{D})(98)$ & \\
1380 & $v(\mathrm{C}=\mathrm{N})(39)+v(\mathrm{~N}-\mathrm{C} \alpha)(12)+$ & \\
& $\phi(\mathrm{C}=\mathrm{N}-\mathrm{D})(15)+\phi(\mathrm{C} \alpha-\mathrm{N}-\mathrm{D})(27)+$ \\
& $v(\mathrm{C}=\mathrm{O})(8)+v(\mathrm{C} \alpha-\mathrm{C})(7)$ & $\{$ Amide $\mathrm{A}\}$ \\
1023 & $v(\mathrm{~N}-\mathrm{C} \alpha)(26)+\phi(\mathrm{C}=\mathrm{N}-\mathrm{D})(15)$ & \\
& $\phi(\mathrm{C} \alpha-\mathrm{N}-\mathrm{D})(27)$ & \\
& & \\
536 & $\omega(\mathrm{N}-\mathrm{D})(47)+\omega(\mathrm{C}=\mathrm{O})(7)+$ & \\
& $\phi(\mathrm{N}-\mathrm{C} \alpha-\mathrm{C})(16)+\tau(\mathrm{C}=\mathrm{N})(5)$ & $\{$ Amide $\mathrm{III}\}$
\end{tabular}

a All frequencies are in $\mathrm{cm}^{-1}$ b $^{\text {b }}$ Freq. frequency. 
$\mathrm{cm}^{-1}$ corresponding to observed band at $1090 \mathrm{~cm}^{-1}$.

\section{Side Chain Modes}

Side chain of poly(L-valine) has a gem dimethyl group. Side chain modes mostly consist of rocking, wagging, twisting modes of $\mathrm{CH}_{3}$ and $\mathrm{C} \beta-\mathrm{C} \gamma, \mathrm{C} \beta-\mathrm{H} \beta, \mathrm{C} \gamma-\mathrm{H} \gamma$ stretching modes. The strong line in the FT-IR spectrum at $1470 \mathrm{~cm}^{-1}$ is assigned to asymmetric $\mathrm{CH}_{3}$ deformation of the gem dimethyl group. The doublet observed at 1394 and 1372 arise from symmetric $\mathrm{CH}_{3}$ deformation of the gem dimethyl group and is calculated at 1391 and $1370 \mathrm{~cm}^{-1}$. Methyl rocking modes are calculated at 1038, 1006, 970, 918, and $873 \mathrm{~cm}^{-1}$ corresponding to observed frequencies at 1037 , $1006,981,907$, and $868 \mathrm{~cm}^{-1}$ respectively. Out of these five modes two modes at 1006 and $918 \mathrm{~cm}^{-1}$ are pure rocking modes and three modes are mixed modes. The modes at 1038 and $868 \mathrm{~cm}^{-1}$ have small contribution from $(\mathrm{C} \alpha-\mathrm{C} \beta)$ stretch while the mode at $970 \mathrm{~cm}^{-1}$ is mixed with $(\mathrm{C} \beta-\mathrm{C} \gamma)$ stretch. The modes calculated at $1350 \mathrm{~cm}^{-1}$ and $1310 \mathrm{~cm}^{-1}$ corresponding to the observed bands at $1343 \mathrm{~cm}^{-1}$ and $1319 \mathrm{~cm}^{-1}$ respectively, are mixture of $\mathrm{H} \alpha$ and $\mathrm{H} \beta$ bendings. In the first case $\mathrm{H} \alpha$ bend is dominent while in the other one $\mathrm{H} \beta$ bend is dominent. The doublet calculated at 203 and $199 \mathrm{~cm}^{-1}$ corresponds to $\left(\mathrm{C} \beta-\mathrm{C} \gamma_{1}\right)$ and $\left(\mathrm{C} \beta-\mathrm{C} \gamma_{2}\right)$ torsions.

\section{Dispersion Curves}

The dispersion of modes below $1400 \mathrm{~cm}^{-1}$ are plotted in Figures 3(a), 4(a), and 5(a). The mode at $371 \mathrm{~cm}^{-1}$ shows maximum dispersion. This mode involves the motion of both, backbone and side-chain atoms and its potential energy distribution (P.E.D.) at $\delta=0$ is $\phi(\mathrm{N}-\mathrm{C} \alpha-$ $\mathrm{C} \beta)(11 \%)+\phi(\mathrm{H} \beta-\mathrm{C} \beta-\mathrm{C} \alpha)(10 \%)+\phi\left(\mathrm{C}_{1}-\right.$ $\mathrm{C} \beta-\mathrm{C} \alpha)(10 \%)+\phi\left(\mathrm{C} \gamma_{1}-\mathrm{C} \beta-\mathrm{H} \beta\right)(11 \%)$. As $\delta$ increases the contributions of side chain motion decreases and at $\delta=\pi$ it becomes a pure backbone mode having $\phi(\mathrm{C} \alpha-\mathrm{C}=\mathrm{O})(12 \%)+$ $\phi(\mathrm{C} \alpha-\mathrm{C}=\mathrm{N})(28 \%)$ and $\phi(\mathrm{N}-\mathrm{C} \alpha-\mathrm{C})(9 \%)$. The

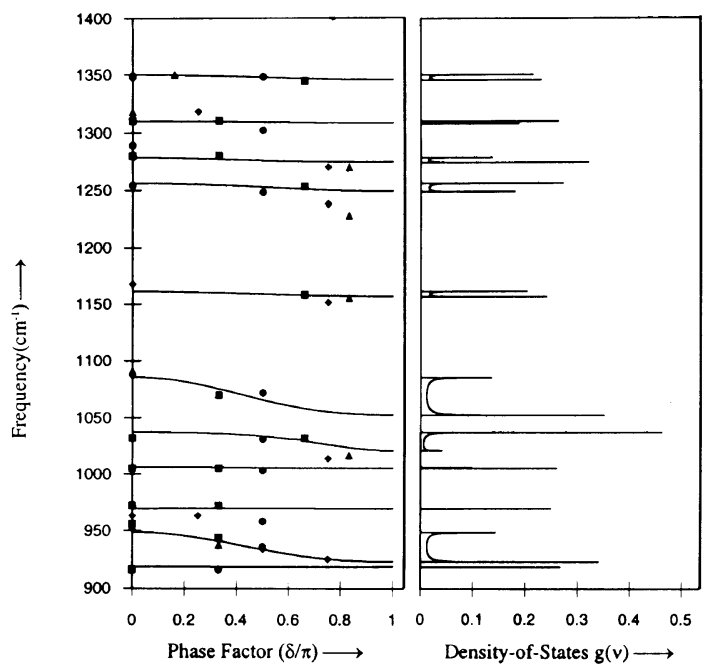

Figure 3. (a) Dispersion curves of Poly(L-valine) and spectral data of oligovalines $[\boldsymbol{O}, \boldsymbol{\square}, \boldsymbol{\nabla}$, and $\boldsymbol{\Delta}$ indicate dimer, trimer, tetramer, and hexamer, respectively] $(1400-$ $\left.900 \mathrm{~cm}^{-1}\right)$. (b) Density-of-states $g(v)\left(1400-900 \mathrm{~cm}^{-1}\right)$.
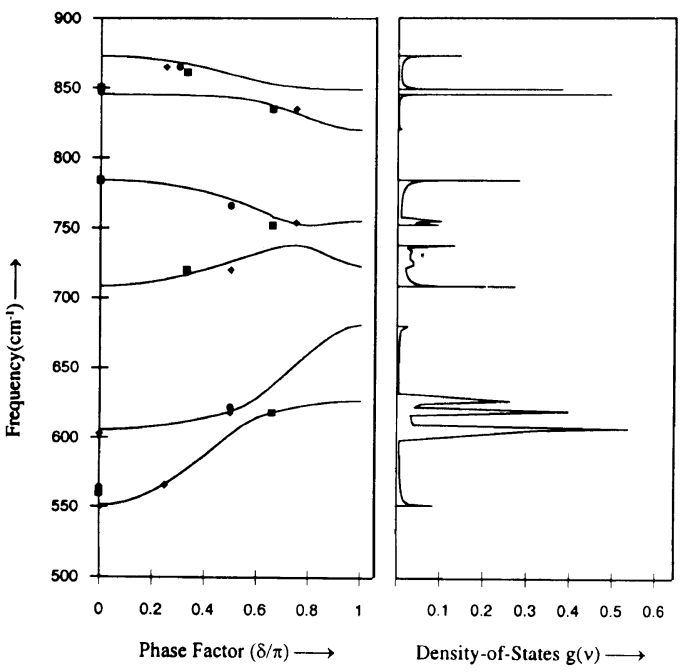

Figure4. (a) Dispersion curves of Poly(L-valine) and spectral data of oligovalines $[\boldsymbol{\nabla}, \boldsymbol{\square}, \boldsymbol{\bullet}$, and $\boldsymbol{\Delta}$ indicate dimer, trimer, tetramer, and hexamer, respectively] $(900-$ $\left.500 \mathrm{~cm}^{-1}\right)$. (b) Density-of-states $g(v)\left(900-500 \mathrm{~cm}^{-1}\right)$.

frequencies that show dispersion are mainlythe backbone and side chain-backbone junction modes. The backbone stretching mode calculated at $1086 \mathrm{~cm}^{-1}$ shows a dispersion of 34 wavenumbers. The frequency of the mode 


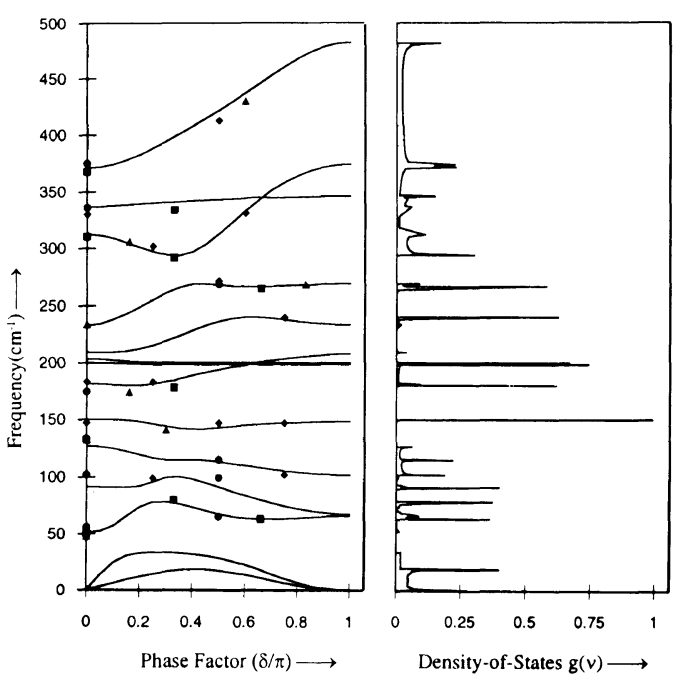

Figure 5. (a) Dispersion curves of Poly(L-valine) and spectral data of oligovalines $[\boldsymbol{\sigma}, \boldsymbol{\square}, \boldsymbol{\bullet}$, and $\boldsymbol{\Delta}$ indicate dimer, trimer, tetramer, and hexamer, respectively] below $500 \mathrm{~cm}^{-1}$. (b) Density-of-states $g(v)$ below $500 \mathrm{~cm}^{-1}$.

at $784 \mathrm{~cm}^{-1}$ which consists of a mixture of $\mathrm{N}-\mathrm{H}$ waig and $\mathrm{C}=\mathrm{O}$ wag, decreases as the value of $\delta$ increases, this mode come closer to the amide $\mathrm{V}$ mode $\left(708 \mathrm{~cm}^{-1}\right)$, the energy of which is continuously increasing with $\delta$ vaule. At $\delta \simeq 0.65 \pi$, percentage contribution of $\mathrm{N}-\mathrm{H}$ wag and $\mathrm{C}=\mathrm{O}$ wag start decreasing in the higher mode $\left(784 \mathrm{~cm}^{-1}\right)$ and goes into the lower mode $\left(708 \mathrm{~cm}^{-1}\right)$. The percentage contribution of $\mathrm{N}-\mathrm{H}$ wag increases very sharply in the lower mode and the energy of this mode starts decreasing while the higher mode takes up a constant value. A repulsion also occurs in the modes at 606 and $551 \mathrm{~cm}^{-1}$. The frequency of $551 \mathrm{~cm}^{-1}$ mode increases very sharply as $\delta$ increases and percentage contributions of $\phi(\mathrm{C} \alpha-\mathrm{C}=\mathrm{O})$ and $\phi(\mathrm{O} \cdots \mathrm{C} \cdots \mathrm{N})$ decrease: The frequency of $606 \mathrm{~cm}^{-1}$ mode increases very slowly and \% contributions of $\mathrm{N}-\mathrm{H}$ and $\mathrm{C}=\mathrm{O}$ wag decrease. At $\delta \simeq 0.5 \pi$, $\omega(\mathrm{N}-\mathrm{H})$ starts mixing with $551 \mathrm{~cm}^{-1}$ mode while $\phi(\mathrm{O} \cdots \mathrm{C} \cdots \mathrm{N})$ starts mixing with 606 $\mathrm{cm}^{-1}$ at $\delta=0.55 \pi$. At $\delta=0.6 \pi$ the two modes exchange their character and the $606 \mathrm{~cm}^{-1}$ mode is repelled up while the lower mode takes up nearly constant value. The mode at 312 $\mathrm{cm}^{-1}$ crosses the $337 \mathrm{~cm}^{-1}$ mode belonging to different symmetry species at $\delta \simeq 0.7 \pi$. The mode at $181 \mathrm{~cm}^{-1}$ which is a bending mode of $\mathrm{C}-\mathrm{C} \alpha-\mathrm{C} \beta$ and $\mathrm{C} \gamma_{1}-\mathrm{C} \beta-\mathrm{C} \gamma_{2}$ cross the $(\mathrm{C} \beta-\mathrm{C} \gamma)$ torsional mode at $\delta=0.65 \pi$. This type of crossing is possible in polymers where the backbone lies on a mirror plane of symmetry. ${ }^{25}$

\section{Interpretation of Spectra of Oligomers from Dispersion Curves}

In the absence of inelastic neutron scattering data one of the easiest ways to test the meandering part of the dispersion curves is to look at the spectra of various oligomers. As discussed earlier the spectra of oligomers are related to the dispersion profile of the polymer modes through the phase relationship given by expression (3) and provided both the oligo- and polymers are confomationally connected. The Raman scattering data on oligomers of valine upto hexamer as reported by Fasman et al. ${ }^{2}$ have been used. The observed modes are assigned at appropriate phase values on the corresponding branch of the dispersion curve from all possible $k$ values and are plotted in Figure 3(a), 4(a), and 5(a) along with the dispersion curve of $(\mathrm{Val})_{n}$. A comparison of some important modes in various oligomers has been given in Table VII. A good agreement of observed frequencies for oligovalines on the corresponding dispersion curves for allowed phase values show that the oligomers of valine upto hexamer have a structure closer to the extended $\beta$ form. In case of divaline there are significant deviations, these could be due to the end group interactions arising due to out of plane conformation of the $\mathrm{COO}^{-}$group with respect to the plane of the atoms in the skeleton $(\mathrm{N}-\mathrm{C} \alpha-\mathrm{C}-\mathrm{N})$. The interactions decay rapidly as chain length increases.

\section{Frequency Distribution Function and Heat Capacity of Poly(L-valine)}

Frequency distribution function as obtained from the dispersion curves is shown in Figures 
L. BURMAN et al.

Table VII. A comparison of amide and some other modes in oligovalines and Poly(L-valines $)^{\mathbf{a}}$

\begin{tabular}{|c|c|c|c|c|c|}
\hline Mode & $n=2$ & $n=3$ & $n=4$ & $n=6$ & $\beta$-PLV \\
\hline \multirow[t]{2}{*}{ Amide I } & $1622(1630)$ & $1655(1637)$ & $1634(1631)$ & - & 1629 \\
\hline & 1660 & 1668 & 1663 & 1663 & \\
\hline Amide II & $1551(1531)$ & $1560(1537)$ & $1565(1537)$ & $1565(1537)$ & 1537 \\
\hline Amide III & $1254(1256)$ & $1253(1255)$ & $1238(1253)$ & $1228(1250)$ & 1256 \\
\hline Amide IV & $564(551)$ & $560(551)$ & $566(566)$ & - & 551 \\
\hline Amide $\mathrm{V}$ & $744(726)$ & $720(715)$ & $720(713)$ & - & 708 \\
\hline Amide IV & $622(619)$ & $618(606)$ & $618(609)$ & - & 606 \\
\hline Amide VII & $133(127)$ & $132(127)$ & $102(106)$ & - & 126 \\
\hline \multirow[t]{2}{*}{$v(\mathrm{~N}-\mathrm{C} \alpha)+v(\mathrm{C} \alpha-\mathrm{C})$} & $1072(1066)$ & $1070(1076)$ & $1087(1080)$ & $1092(1086)$ & 1086 \\
\hline & $1031(1034)$ & $1032(1037)$ & - & - & 1038 \\
\hline Methyl rock & $1003(1006)$ & $1005(1006)$ & $1014(1006)$ & $1017(1005)$ & 1006 \\
\hline \multirow[t]{2}{*}{$v(\mathrm{C} \alpha-\mathrm{C})+v(\mathrm{C}=\mathrm{O})$} & $936(934)$ & $944(941)$ & $954(944)$ & $954(947)$ & 949 \\
\hline & $847(843)$ & $850(845)$ & $835(832)$ & $844(845)$ & 845 \\
\hline$\omega(\mathrm{N}-\mathrm{H})+\omega(\mathrm{C}=\mathrm{O})$ & $766(7.71)$ & $784(784)$ & $754(753)$ & $756(760)$ & 784 \\
\hline Main-chain def. & $269(269)$ & $265(263)$ & $272(268)$ & $269(267)$ & 270 \\
\hline \multirow[t]{2}{*}{ Side-chain def. } & - & - & $147(146)$ & $141(143)$ & 150 \\
\hline & $375(371)$ & $368(371)$ & $400(398)$ & $403(398)$ & 371 \\
\hline
\end{tabular}

a All frequencies are in $\mathrm{cm}^{-1}$ and the figures in parenthesis are the predicted values from the dispersion curves of $\beta$-PLV for $n-2,3,4$, and 6 .

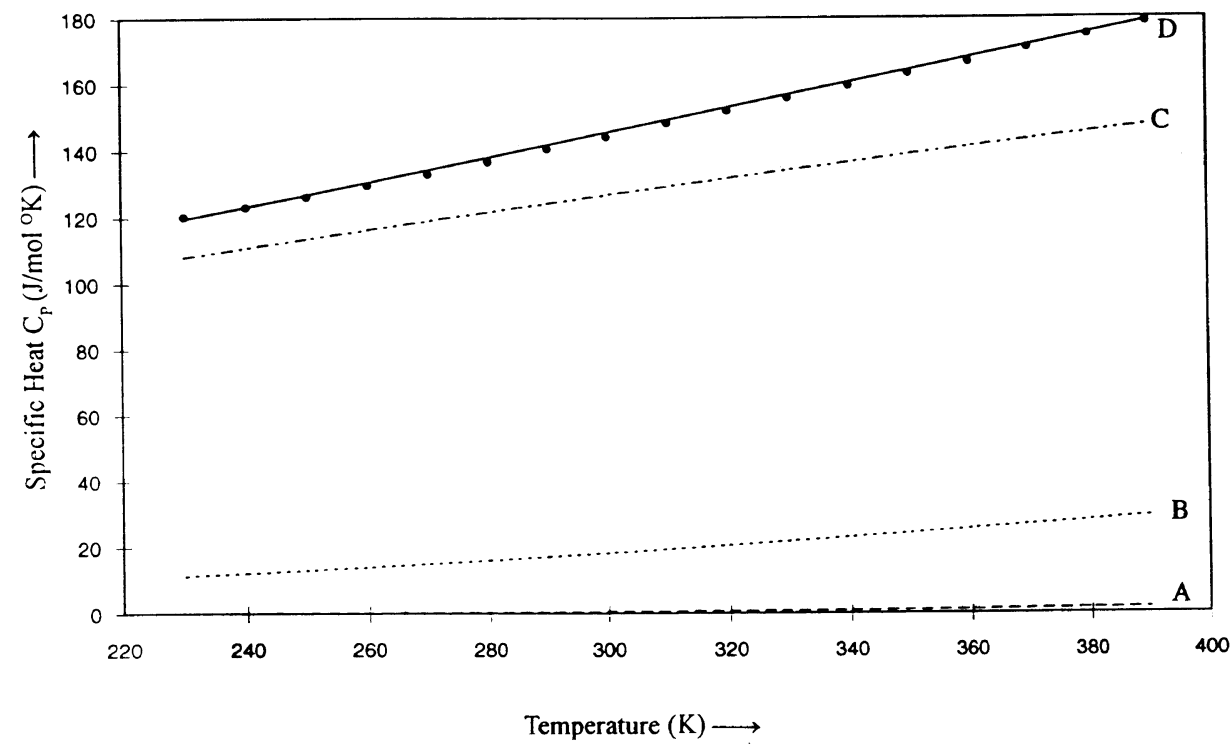

Figure 6. Variation of heat capacity $C_{\mathrm{p}}$ with temperature. $[\mathrm{A} \cdots \cdots, \mathrm{B} \cdots \cdots, \mathrm{C}-\cdots-$, and $\mathrm{D},-$ indicate backbone contribution, side-chain contribution, mixed mode contribution, and total contribution where represents experimental points.

3(b), 4(b), and 5(b). The peaks in the frequency distribution curves correspond to the regions of high density-of-states. The observed frequencies compare well with these peak posi- tions. From this knowledge of density-ofstates, heat capacity of PLV chain has been calculated from $230-390 \mathrm{~K}$. Experimental measurements have been reported by Roles and 
Wunderlich. ${ }^{7}$ They have fitted the data using approximate group vibrations and dispersion curves of polyglycine I, poly(L-alanine) $(\beta$ form) reported by this group. Such an approximation is valid only in the high frequency region. The low frequency modes are much more sensitive to actual conformation of the chain and side groups and there is strong coupling between these modes. Specific heat in the low temprature region is sensitive to $g(v)$ in the low frequency region. Modes which are purely skeletal, purely side chain and mixture of these two are given in Table II, Table III, and Table IV, respectively. Their contributions to the heat capacities are shown in Figures 6A, $6 \mathrm{~B}$, and $6 \mathrm{C}$, respectively in the temperature range $230-390 \mathrm{~K}$. The sum of these three contributions i.e., total heat capacity is shown in Figure 6D and the experimental data of Roles and Wunderlich ${ }^{8}$ is represented by $\bullet$ 's. Our calculations agree well with the experimental data in the whole temperature range. It is clear from Figure 6 that major contribution to the heat capacity comes from backbone and side chain coupled modes.

Acknowledgement. Financial assistance to L.B. and P.T. from the University Grants Commission and to V.D.G. from C.S.I.R. under the Emeritus Scientist Scheme is gratefully acknowledged.

\section{REFERENCES}

1. S. Yamashita and T. Yamashita, Proc. Natl. Acad. Sci. U.S.A., 72, 941 (1975).

2. G. D. Fasman, K. Itoh, C. S. Liu, and R. C. Lord, Biopolymers, 17, 125 (1978).
3. O. Yamashita, T. Yamane, T. Ashida, S. Yamashita, and T. Yamashita, Polym. J., 11, 763 (1979).

4. O. Yamashita and T. Ashida, Polym. J., 15, 899 (1987).

5. B. Wunderlich and H. S. Bu, Thermochimica Acta, 119, 225 (1987).

6. H. S. Bu, W. Aycock, Z. D. Cheng Stephen, and B. Wunderlich, Polymer, 29, 1486 (1988)

7. K. A. Roles and B. Wunderlich, Biopolymers, 31, 477 (1991).

8. K. A. Roles, A. Xenopoulos, and B. Wunderlich, Biopolymers, 33, 753 (1993).

9. V. D. Gupta, S. Trevino, and H. Boutin, J. Chem. Phys., 48, 3008 (1968).

10. M. V. Krishnan and V. D. Gupta, Chem. Phys. Lett., 6, 231 (1970).

11. M. V. Krishnan and V. D. Gupta, Chem. Phys. Lett., 7, 285 (1970).

12. R. D. Singh and V. D. Gupta, Spectrochim. Acta, 27A, 385 (1971).

13. A. M. Dwivedi and V. D. Gupta, Chem. Phys. Lett., 16, 909 (1972)

14. E. B. Wilson, J. C. Decuis, and P. C. Cross, "Molecular Vibrations: The Theory of Infrared and Raman Vibrational Spectra”, DoverPublications, New York, 1980.

15. P. W. Higgs, Proc. Roy. Soc., London, Ser. A, 472 (1953).

16. K. Itoh and G. D. Fasman, Biopolymers, 14, 1755 (1975).

17. B. Fanconi, Biopolymers, 122759 (1973).

18. B. Fanconi, E. W. Small, and W. L. Peticoals, Biopolymers, 10, 1277 (1971).

19. T. H. Benzinger, Nature, 229, 100 (1971).

20. R. Pan, M. Verma-Nair, and B. Wunderlich, $J$. Therm. Anal., 35, 955 (1989).

21. J. L. Koenig and P. L. Sutton, Biopolymers, 10, 89 (1971).

22. S. Krimm and J. Bandekar, J. Adv. Protein Chem., 38, 181.(1986).

23. B. G. Frushour and J. L. Koenig, Biopolymer, 13, 455 (1974).

24. K. Itoh, T. Shimanouchi, and M. Oya, Biopolymers, 7, 649 (1969).

25. D. I. Bower and W. F. Maddams, "The Vibrational Spectroscopy of Polymers", Cambridge University Press, New York, 1989, pp 154-156. 